\title{
Evaluation of the Public's Knowledge, Attitude, and Practice on Seafood Contaminants
}

\author{
Matthew Loo ${ }^{1}$, Helen Heacock ${ }^{2}$, Reza Afshari ${ }^{3}$ \\ ${ }^{1}$ Lead Author, B. Tech Student, School of Health Sciences, British Columbia Institute of Technology, 3700 \\ Willingdon Ave, Burnaby, BC V5G 3H2 \\ ${ }^{2}$ Supervisor, School of Health Sciences, British Columbia Institute of Technology, 3700 Willingdon Ave, Burnaby, \\ BC V5G 3H2 \\ ${ }^{3}$ Contributor, British Columbia Centre for Disease Control, 655 West 12th Ave, Vancouver, BC, V5Z 4R4
}

\begin{abstract}
Background: The public perceives seafood generally as a healthy food. Studies have shown that consumption of fish is associated with healthy heart function. However, the benefits of consuming seafood may also come with some risks, which may not be well-known by the public. Seafood can potentially contain contaminants that originate from the natural environment or pollutants from human activity. The contaminants of interest that were focused on in this study include lead, mercury, organophosphates, and domoic acid.
\end{abstract}

Methods: The study utilized a KAP (Knowledge, Attitude, and Practice) survey to evaluate the knowledge, attitude, and practices regarding these contaminants between the general public and those working in the seafood industry. Nominal data was analyzed by the chi-square test while numerical data was analyzed by the t-test.

Results: The data obtained did not show a statistically significant difference between the general public and the seafood industry ( $\mathrm{p}$-values greater than significance level of 0.05 on all parameters) in their knowledge, attitude, and practice regarding seafood contaminants.

Conclusion: There was no difference between the general public and the seafood industry in their knowledge, attitude, and practice regarding seafood contaminants. Although the attitude data was not significant, the effects of some chemical contaminants (organophosphates and domoic acid) were generally incorrectly perceived by both groups unlike biological contaminants. Additional research will be required, but results from this study show that educational intervention by the government or health authorities may be needed.

Key words: Seafood, contaminants, knowledge, attitude, practice, perception, domoic acid, lead, mercury, organophosphates 


\section{Introduction}

Seafood is an important source of protein and is continuously growing in popularity because of its health benefits. Omega-3 fatty acids, an abundant substance in most fish, are associated with healthy heart function (Health Canada, 2013b). Along with its benefits, however, are contaminants that can pose a health risk to public. Seafood is generally regarded as a healthy food but the toxic substances that can be found in seafood may be less well known by the public (Burger \& Gochfeld, 2009; Verbeke, Sioen, Pieniak, Van Camp \& De Henauw, 2005). For this reason, the BC Centre for Disease Control (BCCDC) has recommended a research project with the purpose of evaluating and comparing knowledge, attitude, and practice regarding various toxins found in seafood between two groups of people: the general public and people who work in the fish and seafood industry. In addition, this study determined whether there were any misconceptions in knowledge in the two groups, which may help shape the focus of future educational programs on seafood safety.

The study utilized a KAP (Knowledge, attitude, and practice) survey designed to collect data on the respondent's knowledge, attitude, and practice on four specific contaminants: mercury, lead, organophosphate residues, and domoic acid. The results were compared between respondents who belong to the general public and those who work in the fish and seafood industry.

\section{Literature Review}

\section{Lead}

Exposures to lead in Canada have been greatly reduced since preventative measures were introduced to minimize the intake through inhalation (Health Canada, 2013a). However, Health Canada (2013a) states that adverse health effects are appearing in blood lead levels below the current intervention level of $10 \mu \mathrm{g} / \mathrm{dL}$. Evidence shows that these effects can arise even when the blood lead level is at $5 \mu \mathrm{g} / \mathrm{dL}$ (Health Canada, 2013a). High levels of lead have been associated with miscarriage in pregnant women and long term exposures has been implicated with developmental problems in the fetus (Wong \& Lye, 2008). Since preventative measures have been implemented, the main exposure route of lead in Canadians has changed to ingestion (Health Canada, 2013a). Lead can be found in the natural environment and can make its way into our seafood supply because fish can absorb lead from water and sediments (Health Canada, 2013a). Lead can also be introduced into food during transportation to markets through contact with contaminated water (Health Canada, 2013c).

\section{Mercury}

There are three forms of mercury: elemental mercury, organic mercury, and inorganic mercury. The form of concern is an organic type known as methylmercury because Canadians are primarily exposed to this form (Wong \& Lye, 2008).

Methylmercury can produce many adverse effects in people if they are continuously 
exposed. These include numbness and tingling in the extremities, blurred vision, deafness, lack of muscle coordination and intellectual impairment, adverse effects on the cardiovascular, gastrointestinal and reproductive systems (Wong \& Lye, 2008). Pregnant women who are exposed to methylmercury risk neurological and developmental delays to the fetus (Grandjean \& Herz, 2011; Hong \& Kim, 2012; Wong \& Lye, 2008). Health Canada (2013b) states that the mercury levels in fish that are commonly eaten in Canada are relatively low. However, overconsumption can still lead to adverse health effects (Health Canada, 2013b). Predatory fish, or fish that consume other fish, tend to have higher levels of mercury due to accumulation through the food chain (Health Canada, 2013b).

\section{Organophosphates}

Organophosphate residues can be found in fish due to the use of organophosphate pesticides (Burridge \& Van Geest, 2014; Verrin, Begg \& Ross, 2004). Originally, these pesticides were used to treat sea lice found in Atlantic salmon in parts of Canada (Burridge \& Van Geest, 2014). One specific brand of organophosphate pesticide, Salmosan $^{\circledR}$, saw usage but was discontinued in 2002 due to increasing resistance in sea lice (Burridge \& Van Geest, 2014). However, in 2009, Salmosan ${ }^{\circledR}$ was given Emergency Registration for use in New Brunswick (Burridge \& Van Geest, 2014). Today, organophosphate pesticides are no longer used in British Columbia to treat sea lice (Burridge \& Van Geest, 2014), but they are still used on other crops. Since most organochlorine pesticides were banned, usage of organophosphate pesticides increased (Verrin et al., 2004). These chemicals can enter nearby streams and are absorbed by the fish that reside there (Verrin et al., 2004). When ingested by humans, organophosphates can cause symptoms such as headaches, weakness, and blurred vision (WorkSafe BC, 2009). In severe cases, symptoms can include muscle twitching, constriction of pupils, bluish skin, convulsions, comas, and death (WorkSafe BC, 2009).

\section{Domoic acid}

Domoic acid can accumulate in shellfish through the consumption of phytoplankton such as the Pseudo-nitzschia species (BCCDC, 2015; DFO, 2015). Accumulation of domoic acid is most commonly found in mussels, but can also affect razor clams, scallops and crustaceans (BCCDC, 2015). Consumption of domoic acid can result in amnesic shellfish poisoning, which is characterized by symptoms such as nausea, vomiting, diarrhea, and short term memory loss (DFO, 2015). In severe cases, brain damage can occur (DFO, 2015). Experiments using a rodent model demonstrated that domoic acid is capable of entering the fetal brain and causes changes in motor behavior and cognition (Grant, Burbacher, Faustman, \& Gratttan, 2010). Although the long-term effects of domoic acid are not well documented (Grant et al., 2010), the phytoplankton that produce domoic acid appear to be increasing both in frequency and in toxicity on a global scale (Lefebvre \& Robertson, 2010). Thus, it will be 
increasingly important to conduct more research to understand the health implications of domoic acid and to educate the public.

\section{Public's perceptions on risk found in seafood}

According to surveys done in Belgium and in the United States, the public believes that seafood is beneficial for human health (Verbeke et al., 2005; Hicks, Pivarnik, \& McDermott, 2008). In the area of risk perception, Verbeke et al. (2005) showed that the respondents had the strongest belief $(45.8 \%)$ that fish were contaminated with heavy metals. The majority of the respondents $(77.3 \%)$ also strongly believed that heavy metals were harmful to human health. The study done by Hicks et al. (2008) demonstrated that a large portion of the respondents $(62 \%)$ felt that seafood contaminants were an important factor in purchasing decisions. However, only 14\% of the respondents felt that they were knowledgeable in seafood contaminants (Hicks et al., 2008). 57\% of respondents mentioned specifically mercury as a negative attribute of seafood (Hicks et al., 2008). Interviews performed in the study by Burger \& Gochfeld (2009) showed that the respondents recognize that both benefits and risks exist with the consumption of fish. However, knowledge was limited in both areas with even less understanding in the risks (Burger \& Gochfeld, 2009). None of the studies specifically addressed the perceptions of organophosphates or domoic acid in seafood. The study by Verbeke et al. (2005) did show that the respondents strongly perceived $(83.1 \%)$ that "pesticides and other chemical residues" had negative effects on health. But a large portion of the respondents had neutral opinions or were unsure $(46.8 \%)$ if fish contained pesticides and other chemical residues (Verbeke et al., 2005).

\section{Strengths and weaknesses of the literature} review

The study performed by Verbeke et al. (2005) evaluated public knowledge and perception based on generically named groups of contaminants such as "pesticides and other chemical residues" and "heavy metals". Because of this, the extent of public knowledge of the specific heavy metals cannot be determined. On the other hand, the study performed by Hicks et al. (2008) had individuals who specifically mentioned mercury as their concern. Burger \& Gochfeld (2009) placed "mercury" in its own category, separate from "chemicals/heavy metals", which emphasized the disparity in knowledge between mercury and the other contaminants. Regardless, there is not enough information to make a clear conclusion on the public's knowledge of these contaminants.

Gaps in research, policy, and knowledge

The health effects of the various contaminants that this research project focused on are generally well-documented. However, Canadian studies on the public's perceptions on risk found in seafood were not available. The studies that were reviewed were performed in different regions and showed both similarities and 
differences in public perception. Although this may not translate directly into what can be expected in Canada, it shows that knowledge in this topic can vary from location to location. These findings are inconclusive, but may signify the need for health authorities to conduct further research to find out the gaps and misunderstandings unique to their respective regions.

\section{Methods}

The data collection was performed by handing out KAP surveys for respondents to complete and by distribution of online versions on Facebook and by e-mail. The purpose of using KAP surveys in a health setting is to identify health issues and any potential causes as well as to evaluate the efficacy of current health intervention programs (Macías \& Glasauer, 2014). The data collection was performed using selfadministered surveys, which were given out in person at various seafood markets across Metro Vancouver. These locations were found by doing an online search on Google. The employees who worked at those markets and the people who were shopping there had the prepared script read to them and were asked for their voluntary participation in the study. If the employees were too busy at the time, they were asked if copies could be left with them to complete on their own time. This was repeated until at least 30 responses had been collected for both general public and industry groups. Inperson data collection was performed during the opening hours of the markets. The online version of the survey was created using
Google Forms and was identical to the paper version. However, the distribution method differed. Facebook was the primary medium for the distribution of the online survey. A post was made containing the information of the study as well as the link to the survey. Respondents were also asked to share the post if possible, in order to further distribute the survey. The built-in functions of Google Forms provided automatic recording of data onto Excel spreadsheets, allowing it to be readily analyzed by SAS (Statistical Analysis System).

After the data from the in-person surveys was collected, it was transferred onto Excel spreadsheets. Data was divided based on question type and group (general public and industry). Once the spreadsheets were prepared, SAS was used to analyze the data.

\section{Results}

\section{Demographics}

The gender distribution for the general public group was $65.63 \%$ female and $34.38 \%$ male. The majority of the group were aged 19-29 $(n=20,62.50 \%)$, held an undergraduate degree $(\mathrm{n}=18,56.25 \%)$, had consumed seafood 1-2 times in the past week ( $\mathrm{n}=19,59.38 \%)$, and were the primary shoppers for seafood in their household $(\mathrm{n}=20,62.50 \%)$.

The gender distribution for the fish/seafood industry group was $26.32 \%$ female and $73.68 \%$ male. The majority of the group were aged $50+(\mathrm{n}=10,52.63 \%)$. A variety of education levels were observed in 
this group, with the highest frequency having an undergraduate degree $(\mathrm{n}=7$, $38.89 \%$ ). Most had consumed seafood 3 times or more in the past week $(\mathrm{n}=11$, $57.89 \%$ ), and were also the primary shoppers for seafood in their household $(\mathrm{n}=14,77.78 \%)$.

\section{Knowledge}

The mean knowledge score for the general public was 12.78 while the mean score for the fish/seafood industry was 14.15. The maximum score possible is 20 . The standard deviation was 3.26 for the general public and 2.96 for the fish/seafood industry. A visual distribution of the scores between the two groups can be found in Figure 1.

For the knowledge data set, a two-tailed t-test was used for analysis. According to the
Mann-Whitney U test, the two-sided pvalue was 0.24 . Therefore, it can be concluded that there is no statistically significant difference between the general public and the fish and seafood industry in their knowledge of seafood contaminants.

\section{Attitude}

The chi-square test was used to analyze the data for attitude data set. Fisher's exact test was also performed, because $25 \%$ of the expected counts fell below 5 . There was no $\mathrm{p}$-value for viruses because all respondents in both groups indicated that they believed viruses were bad for human health. The rest of the p-values, however, exceeded 0.05 . Therefore, it can be concluded that there is no statistically significant association between attitude towards seafood

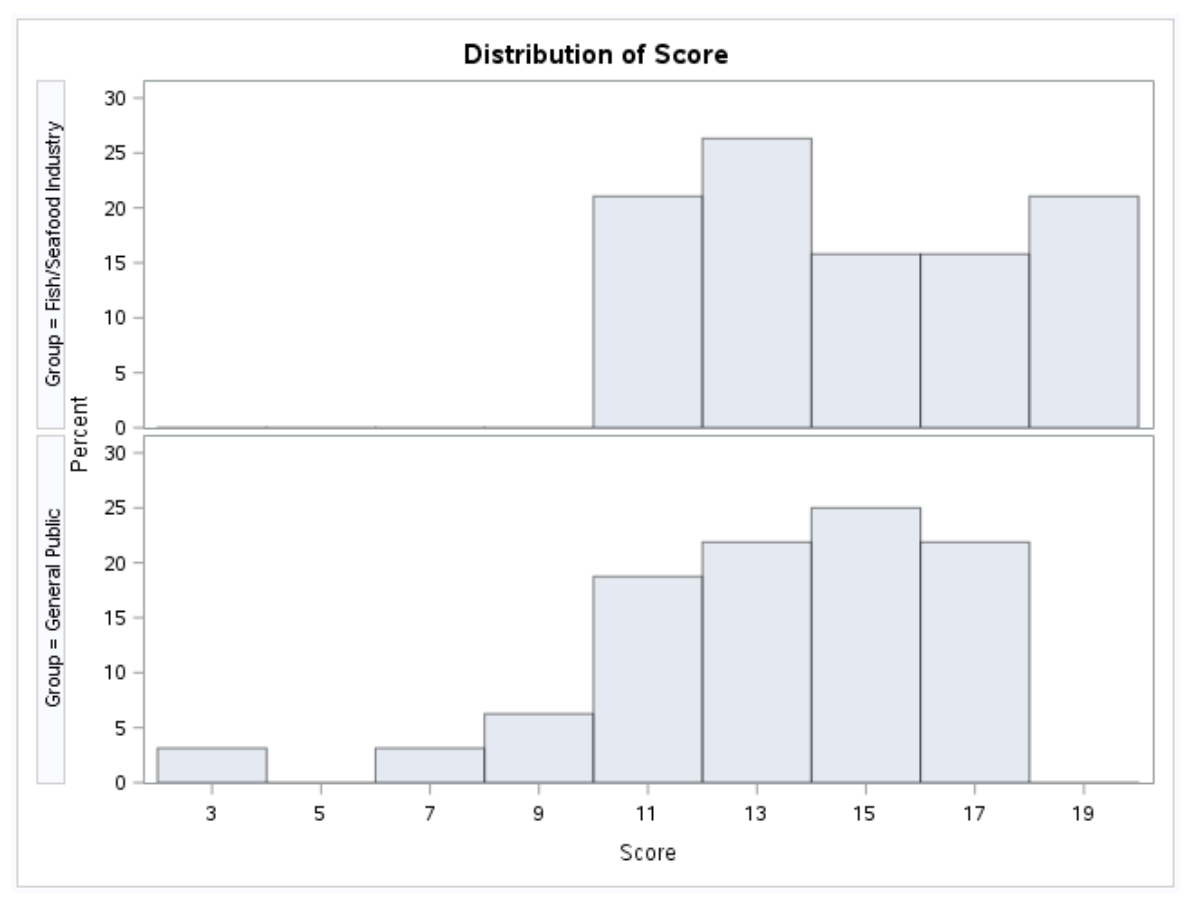

Figure 1: Distribution of knowledge scores for general public and industry. General public scores are more varied while industry scores tend to be on the high end. 
contaminants and whether a person belonged to the general public or the industry.

Table 1: P-values for each component in the attitudes section. There is no association in attitude between general public and industry.

\begin{tabular}{|l|l|}
\hline Components & P-value \\
\hline Microbes & 0.49 \\
\hline Parasites & 0.52 \\
\hline E. coli & 0.69 \\
\hline Viruses & $\mathrm{n} / \mathrm{a}$ \\
\hline Domoic acid & 0.13 \\
\hline Lead & 0.37 \\
\hline Mercury & 0.23 \\
\hline Organophosphates & 0.14 \\
\hline Artificial colouring & 0.37 \\
\hline Dietary fibre & 0.28 \\
\hline Omega-3 fatty acids & 0.52 \\
\hline
\end{tabular}

\section{Practice}

The mean practice score for the general public was 8.31 while the mean score for the fish/seafood industry was 10.26 . The maximum score possible is 16 . The standard deviation was 4.69 for the general public and 4.95 for the fish/seafood industry. This means the scores for the fish/seafood industry were slightly more further apart from the mean compared to those of the general public. A visual distribution of the scores between the two groups can be found in Figure 2.

Similar to the knowledge data set, the data set from the practice section was analyzed by a two-tailed t-test. According to the Mann-Whitney U test, the two-sided pvalue was 0.18 . Therefore, it can be concluded that there is no statistically significant difference between the general public and the fish and seafood industry regarding their practices in avoiding seafood contaminants.

\section{Discussion}

Based on the results of the study, the average knowledge score was $64 \%$ for the general public and $71 \%$ for the industry. The average practice score was $52 \%$ for the general public and $64 \%$ for the industry. Using the threshold levels recommended by the Food and Agriculture Organization of the United Nations (Macías \& Glasauer, 2014), knowledge on seafood contaminants would be considered "low" for the general public and "medium" for the industry. The practice levels for both groups would be "low" also. A "low" score indicates the need for intervention while a "medium" score may or may not require intervention.

Attitude results (See Table 2) show that both the general public and industry perceive correctly for the biological contaminants and the beneficial components. Attitudes toward microbes had varying results for both groups. This may be due to the fact that not all microbes are harmful. Some are not only beneficial to human health, but vital to the existence of human life (National Institute of Allergy and Infectious Diseases, 2015). Nearly all respondents from both groups agreed that parasites, E. coli, and viruses are harmful to human health when found in seafood. Similarly, nearly all respondents from both groups agreed that dietary fibre and omega-3 fatty acids are beneficial for 


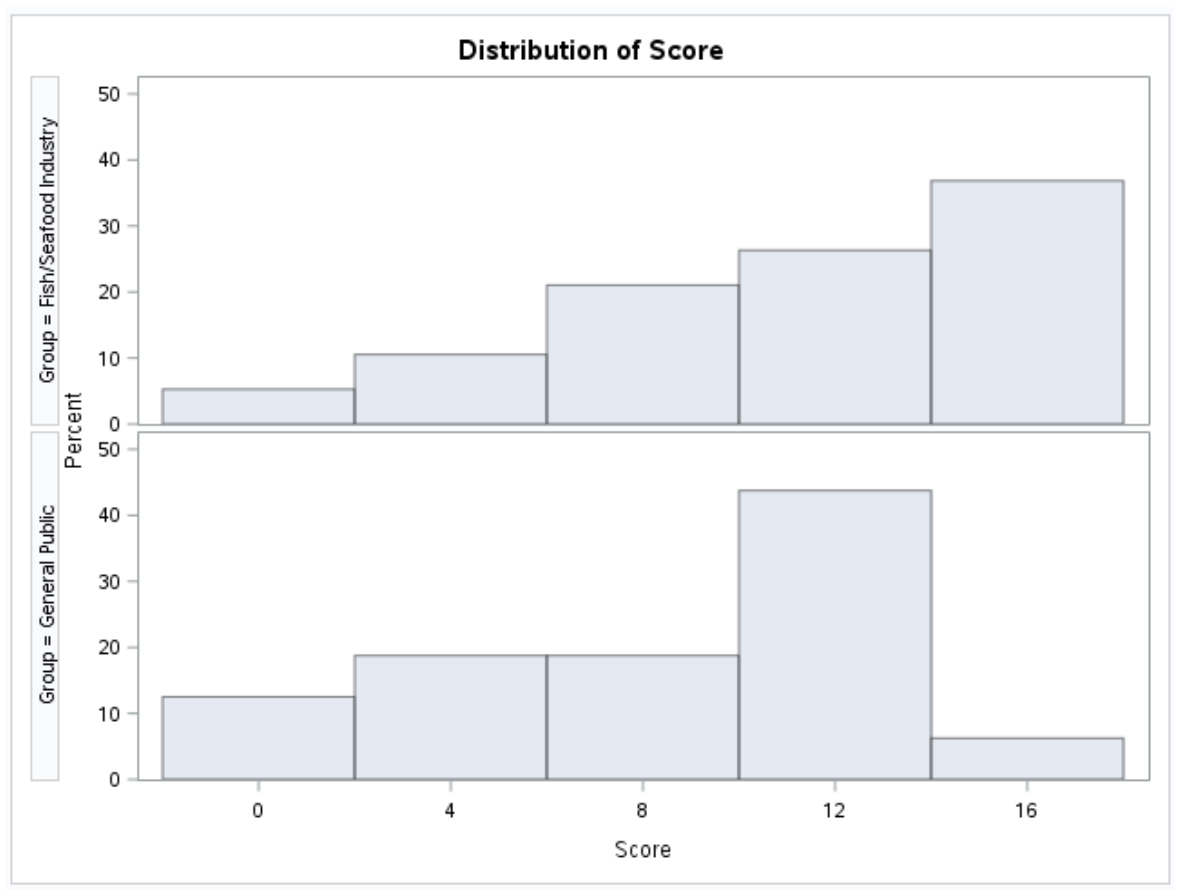

Figure 2: Distribution of practice scores for general public and industry. Both groups had variable scores, but the highest scores were found among the industry group.

human health. Attitudes were split between "neither" and "bad" for artificial colouring in both groups. Artificial colouring or colouring additives are reviewed for their safety before they are allowed to be used in food. However, the term "artificial" may carry negative connotations. Due to an increasingly health-conscious society, there is a trend towards the consumption of natural foods and ingredients, while avoiding artificial alternatives (Agriculture and Agri-Food Canada, 2010).

Both groups perceive correctly that lead and mercury pose negative effects on human health. High levels of lead have been associated with miscarriage in pregnant women and long term exposures has been implicated with developmental problems in the fetus (Wong \& Lye, 2008). Individuals exposed to high levels of methylmercury, the most abundant form of mercury in seafood, can suffer from health effects such as numbness and tingling in the extremities, blurred vision, deafness, lack of muscle coordination and intellectual impairment, adverse effects on the cardiovascular, gastrointestinal and reproductive systems (Wong \& Lye, 2008). In addition, methylmercury exposure presents the risk of neurological and developmental delays to fetuses in pregnant women (Grandjean \& Herz, 2011; Hong, Kim, \& Lee, 2012; Wong \& Lye, 2008).

A large proportion of respondents in both groups are unsure of the health effects of domoic acid and organophosphates. Domoic acid is the cause of amnesic shellfish poisoning, which is characterized by symptoms such as nausea, vomiting, diarrhea, and short term memory loss (DFO, 
Table 2: Summary of attitudes toward tested components

\begin{tabular}{|l|l|l|l|l|l|l|l|l|}
\hline \multirow{2}{*}{ Component } & \multicolumn{4}{|l|}{ General Public } & \multicolumn{3}{l|}{ Fish and Seafood Industry } \\
\cline { 2 - 9 } & Good & Neither & Bad & $\begin{array}{l}\text { Not } \\
\text { sure }\end{array}$ & Good & Neither & Bad & $\begin{array}{l}\text { Not } \\
\text { sure }\end{array}$ \\
\hline Microbes & $15.63 \%$ & $25 \%$ & $40.63 \%$ & $18.75 \%$ & $5.26 \%$ & $21.05 \%$ & $63.16 \%$ & $10.53 \%$ \\
\hline Parasites & $0 \%$ & $0 \%$ & $100 \%$ & $0 \%$ & $0 \%$ & $6.25 \%$ & $93.75 \%$ & $0 \%$ \\
\hline E. coli & $0 \%$ & $6.25 \%$ & $90.63 \%$ & $3.13 \%$ & $0 \%$ & $0 \%$ & $100 \%$ & $0 \%$ \\
\hline Viruses & $0 \%$ & $0 \%$ & $100 \%$ & $0 \%$ & $0 \%$ & $0 \%$ & $100 \%$ & $0 \%$ \\
\hline Domoic acid & $0 \%$ & $9.38 \%$ & $21.88 \%$ & $68.75 \%$ & $10.53 \%$ & $5.26 \%$ & $36.84 \%$ & $47.37 \%$ \\
\hline Lead & $0 \%$ & $3.13 \%$ & $87.5 \%$ & $9.38 \%$ & $0 \%$ & $0 \%$ & $100 \%$ & $0 \%$ \\
\hline Mercury & $0 \%$ & $0 \%$ & $90.63 \%$ & $9.38 \%$ & $0 \%$ & $0 \%$ & $94.74 \%$ & $5.26 \%$ \\
\hline Organophosphates & $6.25 \%$ & $0 \%$ & $28.13 \%$ & $65.63 \%$ & $5.26 \%$ & $10.53 \%$ & $42.11 \%$ & $42.11 \%$ \\
\hline Artificial colouring & $0 \%$ & $50 \%$ & $40.63 \%$ & $9.38 \%$ & $0 \%$ & $31.58 \%$ & $63.16 \%$ & $5.26 \%$ \\
\hline Dietary fibre & $93.75 \%$ & $0 \%$ & $0 \%$ & $6.25 \%$ & $94.74 \%$ & $0 \%$ & $5.26 \%$ & $0 \%$ \\
\hline Omega-3 fatty acids & $93.75 \%$ & $0 \%$ & $0 \%$ & $6.25 \%$ & $100 \%$ & $0 \%$ & $0 \%$ & $0 \%$ \\
\hline
\end{tabular}

2015). In addition, the frequency and toxicity of the phytoplankton producing domoic acid was observed to be increasing over time (Lefebvre \& Robertson, 2010). Organophosphate residues can be found in fish due to the use of organophosphate pesticides (Burridge \& Van Geest, 2014; Verrin, Begg \& Ross, 2004). A small proportion of respondents (10.53\%) from the industry group believed that domoic acid is beneficial to human health. A potential reason why some people may confuse domoic acid for being beneficial is because there are compounds that are good for human health that are also acids. Example of this are omega-3 fatty acids and ascorbic acid (Vitamin C). A small proportion of respondents from both groups (General public $=6.25 \%$, industry $=5.26 \%$ ) believed that organophosphates are beneficial to human health. Organophosphates may have been perceived as beneficial because of the "organo" prefix. With current trends in healthy eating and the rising popularity of organic foods (Agriculture and Agri-Food Canada, 2010), it is not difficult to understand that the name of organophosphates can be misunderstood.

The study performed by Verbeke et al (2005) showed that the respondents had the strongest belief (45.8\%) that fish were contaminated with heavy metals. The majority of the respondents $(77.3 \%)$ also strongly believed that heavy metals were harmful to human health. In addition, the respondents strongly perceived $(83.1 \%)$ that "pesticides and other chemical residues" had negative effects on health. But a large portion of the respondents had neutral opinions or were unsure (46.8\%) if fish contained pesticides and other chemical residues (Verbeke et al., 2005). The heavy metals assessed in this study were lead and mercury. In comparison, results from this study indicated that $54.9 \%$ of all respondents believed that lead was present in seafood (See Table 3). 94.12\% of all respondents believed that mercury was present in seafood. $92.16 \%$ of all respondents believed that lead and mercury was harmful to human health. These results show an increase compared to the study by Verbeke et al. 
(2005), which was performed more than 10 years ago.

Rather than assess for knowledge of pesticides in general, only organophosphates, which come from organophosphate pesticides, were included. $31.37 \%$ of all respondents indicated that organophosphates could be found in seafood. In terms of health effects, the respondents were split between "bad" and "not sure". This indicates that many respondents did not know where organophosphates originate from. It's possible that many more respondents would respond with "bad" if they were asked about pesticides in general instead of organophosphates.

Table 3: Proportion of respondents that indicated that lead/mercury/organophosphates are present in seafood

\begin{tabular}{|l|l|l|l|}
\hline & General Public & $\begin{array}{l}\text { Fish and Seafood } \\
\text { Industry }\end{array}$ & Total \\
\hline Lead & $43.25 \%$ & $73.68 \%$ & $54.9 \%$ \\
\hline Mercury & $93.75 \%$ & $94.74 \%$ & $94.12 \%$ \\
\hline Organophosphates & $28.13 \%$ & $36.84 \%$ & $31.37 \%$ \\
\hline
\end{tabular}

\section{Recommendations}

Based on the limitations of this study, it is recommended to develop a survey with a greater number of questions with a higher level of complexity in order to more accurately assess knowledge, attitudes, and practices regarding seafood contaminants. If online surveys are to be used, the pilot test should be conducted on a variety of electronic devices to minimize any technical issues that may arise on certain devices.

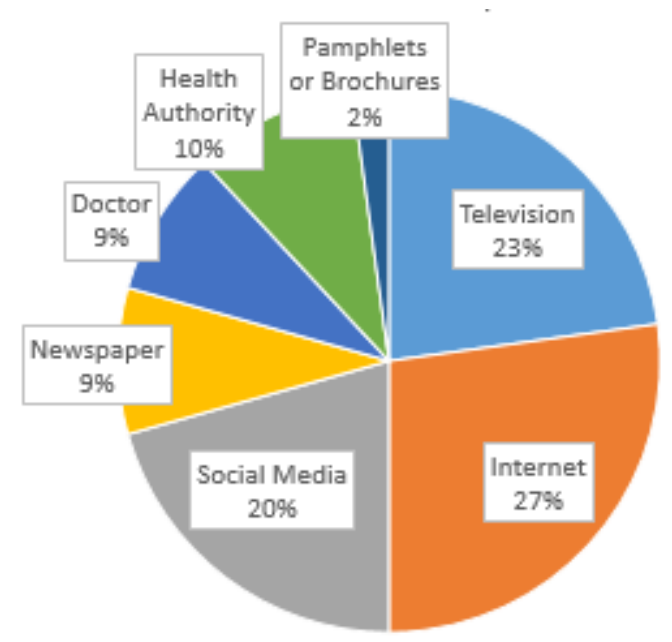

Figure 3: Proportion of Sources of Information on Seafood Contaminants Used (General Public)

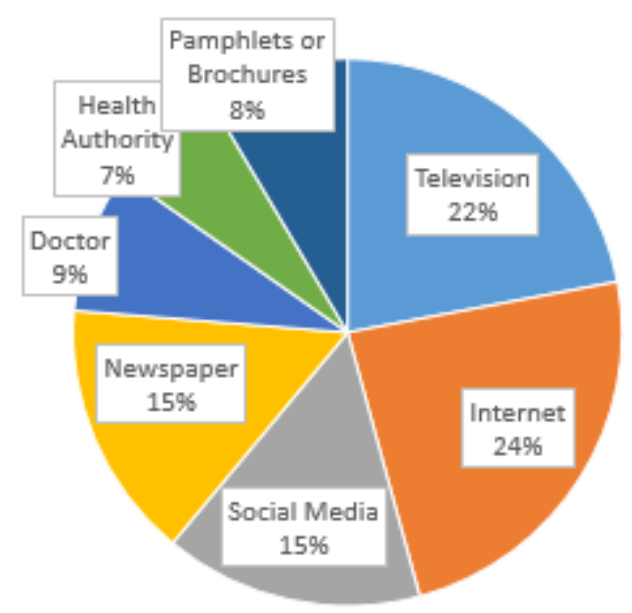

Figure 4: Proportion of Sources of Information on Seafood Contaminants Used (Industry)

Following the results of this study, there needs to be an increase in the dissemination of information regarding domoic acid and organophosphates. Respondents indicated that the top three sources of information that they referred to the most included television, Internet, and social media (See Figure 3 and 4). It is recommended for educational material to be distributed using these avenues in order to achieve the broadest number of people. 


\section{Limitations}

The study used both written surveys and online surveys. This may have had an impact on the willingness to participate in the study and quality of the results. Written surveys tend to demand more attention to the details while the online method may encourage respondents to simply complete the survey as quickly as possible.

The survey was designed to be completed in a short period of time in order to attract respondents to participate as well as for ease of analysis. However, this would mean that the survey cannot ask questions that are too complex or have too many questions. This resulted in a relatively simple survey that is limited in scope and cannot fully and truly assess knowledge, attitude, and practices of the respondent. The study can be improved by increasing the quantity and complexity of the questions. An example would be to assess whether respondents could associate specific illnesses and health effects to each contaminant.

Some respondents indicated that they had difficulty navigating the online version of the survey on mobile devices such as phones and tablets. There were no complaints regarding navigation difficulties on computers and laptops. This problem may have deterred potential respondents from participating in the study. It is unknown whether the problem originates from Google Forms or with the mobile device.

Results from the industry group could possibly be biased. The majority of the respondents from that group indicated that they were "working in the sale of seafood to the public" or "working in the commercial fishing industry". There was only one response each for "fishing guides" and "provincial or federal fisheries department". This uneven distribution of professions within the group means that the results are only representative of those "working in the sale of seafood to the public" or "working in the commercial fishing industry" and not the other professions. In addition, there were only 19 responses from the industry group. A low sample size reduces the ability of the results to be generalized to a larger population.

\section{Future Research}

There are potential research projects that could be built upon this study. Since it was found that the average practice score was low, a study can be conducted to assess the barriers preventing the public from educating themselves on seafood contaminants. By addressing these barriers, the public can gain knowledge and make informed choices when purchasing and consuming seafood. Another option would be to assess knowledge, attitude, and practice regarding seafood contaminants between people who eat seafood and those who do not and the reasons behind their choice.

\section{Conclusion}

The results of this study did not indicate any statistically significant difference 
between the general public and the fish and seafood industry in their knowledge, attitudes, and practices regarding seafood contaminants. Despite this, it appeared that overall knowledge of biological contaminants have improved when compared to a previous study that assessed similar parameters. Areas that were noted to be deficient included the knowledge and attitudes toward domoic acid and organophosphates.

\section{Acknowledgements}

The author would like to thank Helen Heacock for providing support and guidance throughout the course of this study and Reza Afshari for providing advice and expertise on the subject and towards the making of the survey.

\section{Competing Interests}

The authors declare that they have no competing interests

\section{References}

Agriculture and Agri-Food Canada. (2010). Health and Wellness Trends. Retrieved from

https://www.gov.mb.ca/agriculture/marke $\mathrm{t}$-prices-and-statistics/tradestatistics/pubs/us_health_wellness_en.pdf

BC Centre for Disease Control. (2015). Amnesic shellfish poisoning. Retrieved
October 17, 2015 from

http://www.bccdc.ca/dis-cond/az/_a/AmnesicShellfishPoisoning/Overvie w.htm

Burger, J., \& Gochfeld, M. (2009).

Perceptions of the risks and benefits of fish consumption: individual choices to reduce risk and increase health benefits. Environmental Research, 109(3), 343349.

Burridge, L. E., \& Van Geest, J. L. (2014). A Review of Potential Environmental Risk Associated with the Use of Pesticides to Treat Atlantic Salmon Against Infestations of Sea Lice in Canada. Fisheries and Oceans Canada, Science.

Fisheries and Oceans Canada. (2015). Domoic Acid Poisoning. Retrieved October 16, 2015 from http://www.pac.dfo-mpo.gc.ca/fmgp/contamination/asp-eng.html

Grandjean, P., \& Herz, K. T. (2011). Methylmercury and Brain Development: Imprecision and Underestimation of Developmental Neurotoxicity in Humans. Mount Sinai Journal Of Medicine, 78(1), 107-118. doi:10.1002/msj.20228

Grant, K. S., Burbacher, T. M., Faustman, E. M., \& Gratttan, L. (2010). Domoic acid: Neurobehavioral consequences of exposure to a prevalent marine biotoxin. Neurotoxicology and teratology, 32(2), 132-141.

Health Canada. (2013a). Lead. Retrieved October 16, 2015 from http://www.hc- 
sc.gc.ca/ewh-semt/contaminants/leadplomb/index-eng.php

Health Canada. (2013b). Mercury in Fish. Retrieved October 16, 2015 from http://www.hc-sc.gc.ca/fnan/securit/chemchim/environ/mercur/cons-adv-etudeng.php

Health Canada. (2013c). Risk Management Strategy for Lead. Retrieved October 16, 2015 from http://www.hc-sc.gc.ca/ewhsemt/pubs/contaminants/prms_leadpsgr_plomb/index-eng.php

Hicks, D., Pivarnik, L., \& McDermott, R. (2008). Consumer perceptions about seafood-an Internet survey. Journal of Foodservice, 19(4), 213-226.

Hong, Y.-S., Kim, Y.-M., \& Lee, K.-E. (2012). Methylmercury Exposure and Health Effects. Journal of Preventive Medicine and Public Health, 45(6), 353363.

http://doi.org/10.3961/jpmph.2012.45.6.3 53

Lefebvre, K. A., \& Robertson, A. (2010). Domoic acid and human exposure risks: a review. Toxicon, 56(2), 218-230.

Macías, Y. F., \& Glasauer, P. (2014). Guidelines for assessing nutrition-related Knowledge, Attitudes and Practices.

Retrieved from http://www.fao.org/docrep/019/i3545e/i3 $545 \mathrm{e} 00 . \mathrm{htm}$

Microsoft (2016). Microsoft Office Excel 2016. Microsoft Corporation.
National Institute of Allergy and Infectious Disease. (2015). Microbes. Retrieved from http://www.niaid.nih.gov/topics/microbes /Pages/default.aspx

SAS (2016). SAS University Edition [Software]. Available from http://www.sas.com/en_us/software/unive rsity-edition/download-software.html

Verbeke, W., Sioen, I., Pieniak, Z., Van Camp, J., \& De Henauw, S. (2005). Consumer perception versus scientific evidence about health benefits and safety risks from fish consumption. Public health nutrition, 8(04), 422-429.

Verrin, S. M., Begg, S. J., \& Ross, P. S. (2004). Pesticide use in British Columbia and the Yukon: an assessment of types, applications and risks to aquatic biota. Can. Tech. Rep. Fish. Aquat. Sci./Rapp. Tech. Can. Sci. Halieut. Aquat., (2517), 225.

Wong, S. L., \& Lye, E. J. (2008). Lead, mercury and cadmium levels in Canadians. Health Rep, 19(4), 31-6.

WorkSafe BC. (2009). Standard Practices for Pesticide Applicators. Retrieved October 17, 2015 from http://www.worksafebc.com/publications/ health_and_safety/by_topic/agriculture/d efault.asp 